Mini Review

\title{
An overview of antimicrobial resistance and its public health significance
}

\author{
Livia Carminato Balsalobre, Milena Dropa, Maria Helena Matté \\ Laboratório de Saúde Pública, Faculdade de Saúde Pública, Universidade de São Paulo, São Paulo, SP, Brazil.
}

Submitted: March 27, 2012; Approved: April 01, 2013.

\begin{abstract}
Multiple papers have been published regarding the bacterial resistance theme over the last years. A variety of information has reached general and scientific public, daily bringing up data on new resistant microorganisms, new drugs, outbreaks, epidemiological news, resistance gene dissemination, and the lack of information in a particular field has caught our attention: the public health department. Most of researchers, physicians and government employees interpret the public health field as a separate department, not linked to this antibiotic resistance era that we are living nowadays. In this paper we carefully tried to fill in the blanks between public health and the bacteria resistance issue, also considering historical, social, economical and biological problematic that come with this possible pre-antibiotic era.
\end{abstract}

Key words: antimicrobial resistance, public health, pre-antibiotic era.

\section{A Public Health Crisis}

"What do you do when you're faced with an infection, with a very sick patient, and you get a lab report back and every single drug is listed as resistant?" asked Dr. Fred Tenover of Center for Disease Control and Prevention (CDC). "This is a major blooming public health crisis."

\section{A Glimpse of the Resistance History}

Bacterial resistance is not a new phenomenon in our society. Since the beginning of antibiotic usage in therapeutics medicine, the health care system is being challenged by this problematic (Barbosa and Levi, 2000; Thomas, 2009). It does not represent only one field disaster; it involves a diverse group of sectors: political, economical, biological, social and ecological with unknown outcomes and no immediate solution.

The appearance of penicillin resistance occurred in the 40 's, just after the large scale antibiotic usage and while doctors, pharmacists and microbiologists accompanied the rise of the resistance until the mid 80's the global picture started to be treated as a permanent and rising problem and as a threat to the Public Health system (Edgar et al., 2009; Thomas 2009; Wiesch et al., 2011).
The history of bacterial infectious diseases can be divided in three eras: the pre-antibiotic era, the antibiotics era and the antibiotic resistance emergence era. The emergence of resistance in the current world created a risky, but necessary situation regarding the patient treatment, because when facing a bacterial infection the most powerful antibiotics classes are preserved as last resource in therapy, although bacteria already possess mechanisms of making these classes ineffective (Gottlieb and Nimmo, 2011; Siegel, 2008). Therefore, in the last decade the changes in the susceptibility scenario had a drastic impact in the therapeutic options in treating community-acquired and hospitalacquired infections (Rice, 2009; Svara and Rankin, 2011).

The return to the pre-antibiotic era is becoming an imminent reality in many parts of the world (Giamarellou, 2010; Souli et al., 2008), making evident that we are entering an era where the gains that the antibiotics will bring will be minimal, therefore it has never been more important to know the details of mechanisms and the routes of resistance so that therapies, practices, surveillance and research can be adjusted, minimizing the increase of resistance in the future.

The increasing prevalence of resistant and multiresistant bacterial strains has become a serious problem to health care systems all over the world (Högberg et al., 
2010; Munir and Xagoraraki, 2011). From the economical point of view, infections caused by multi-resistant organisms are a constant concern, because its therapeutic management represents a substantial increase of costs for the health system. The economic impact of antimicrobial choices in multi-resistant infections is an increasing problem since a number of researches document the huge extra cost in the health care system, highlighting the caution in the antibiotic prescriptions and the search for information on old and new drugs and on their efficacy (Wilke, 2010).

Every new antibiotic class that arises is followed by the emergence of resistance to this and other classes, leaving patients vulnerable to infections that are not treatable by any of the available antibiotics. Even the newest antimicrobial classes, with a broad spectrum activity, are already being associated to the decrease in susceptibility levels (Kouyos et al., 2011; Santos et al., 2008).

It is known that the group of multi-resistant bacteria usually causes more damage to the infected patients when compared to those outcomes of patients afflicted by susceptible strains from the same species. This data can be seen in infections caused by bacteria such as Klebsiella pneumoniae, Acinetobacter baumannii, Pseudomonas aeruginosa, Enterobacter, and others. The reason for such unsatisfactory results is not necessarily linked to the virulence profile of the strain, but to the antimicrobial empiric treatment that was given to these patients in the beginning of the infection (Isturiz, 2010).

\section{The Antibiotics vs. Bacteria Race}

Every time a drug is prescribed to a patient, all bacteria whether is the target of infection or not are reached, causing a survival pressure over these bacteria, leading to the rise of antimicrobial resistance, which is an evolutionary process characterized by the competition between the resistant and sensitive strains. These processes can occur, individually; in patients, asymptomatic populations or in the environment (Wiesch et al., 2011).

The world accompanies bacterial adaptation against old and new launched drugs, and repetitively we experience crises that affect the government, hospitals committees, pharmaceutical companies, researchers and the population, which frequently return to the square one in protocols and antimicrobial therapy councils.

Despite the efforts to improve antibiotics, bacteria continue to evolve in response to the drugs they are exposed to, and in many cases the organisms present in the environment already possess resistance to antimicrobials there are still in the approval process by FDA (Food and Drug Administration) (Bush, 2004).

The reasons for antimicrobial resistance increase are complex, but through the studies it has become evident that the excessive use of antibiotic is linked to the selection and emergence of resistance. This increase and spread can also be associated to the host population structure, which mainly occurs due to the interaction of the hospital and community (Huttner et al., 2010; Kouyos et al., 2011).

Several infection control measures, aiming public health and improvement of life quality were described over the years. Worldwide campaigns are being launched to fight, remedy or minimize the damages caused by resistant and multi-resistant bacteria, but these interventions require a balance between the individual right and the population protection.

Surprisingly, despite the dogma created a few years ago, the increase and spread of resistance is not caused or restrict only to hospitals and the excessive use of antibiotics. The presence of resistant bacteria strains in sewage, water, food, soil and others, demonstrates the participation of environmental pressure on these strains, and by associating these data with the presence of antibiotics in the environment, its use in veterinarian therapy and agriculture, researches from all over the world are expanding their studies outside the hospitals.

\section{An Unexpected, but Induced Enemy}

It is estimated that approximately $5 \times 10^{30}$ bacteria cells exist in the planet, most not pathogenic organisms. These bacteria interact with a variety of chemical substances in the environment, produced by other bacteria, fungi, plants, animals or by man itself (Wright, 2010; Zhang et al., 2009). Considering the environmental problems caused by these chemicals, dissemination, persistence and emergence of resistant bacteria are directly associated. The increase in the evidences that correlate the clinical and environmental resistance highlights that information and researches in this field must be expanded, including pathogenic and non-pathogenic microorganisms.

The genetic adaptability gives bacteria a huge advantage over mankind. A polluted and anthropologically affected environment withholds a resistance reservoir, where a diverse of bacteria species and even genus; maintain, develop and exchange genetic determinants that constitute a risk to human and ecological health.

Studies have been searching for the presence of resistance genes in bacteria isolated from non-clinical sources, such as food, water, soil, sewage and others. However, the role of the environment in the origin and transmission of resistance is a theme that requires more investigation (Ansari and Malik, 2009; Balsalobre et al., 2010; Dropa et al., 2009; Lachmayr et al., 2009; Moura et al., 2007; Prado et al., 2008).

Our background experience also indicates that temporal researches are important in elucidating the environment involvement in bacteria resistance. Culture collections from different period of time are an important source of information when combined with new data. Genotypic and phenotypic changes can be detected in these collections, which also results in a timeline data interpretation of 
distribution, persistence, dissemination and mobility of important antibiotic resistance markers.

Most resistance genes are acquired by horizontal transfer of genetic mobile elements, harmless in the beginning. However, they have consequently followed the uncontrolled use of antibiotics and became vectors of antimicrobial resistance. Despite the absence of direct information, it is speculated that the origin of these resistance genes is the environmental resistome (Balsalobre et al., 2010; Dropa et al., 2009; Wilke 2010).

\section{Antibiotic Resistance: Social, Economical and Biological Aspects}

The history of efforts to control infectious pathogens shows a concerning fact: as the antimicrobials were use by long periods, the bacteria resistance evolved. This resistance has substantially decreased our ability in controlling several important diseases, leading not only to economic losses, but also to social damages in the Public Health field (Munir and Xagoraraki, 2011; Wiesch et al., 2011).

The bacteria resistance, a worldwide process that has known a rapid and uncontrolled growth in the last two decades, is nowadays accepted as one of the major public health problems. It manifests the increase of infection or the prolonged clinical symptomatology, increase in hospital stay, and not less important, the rise of costs to the health system (Coculescu, 2009; Edgar et al., 2009; Högberg et al., 2010; Huttner et al., 2010; Kurek et al., 2011; Savara and Rankin, 2011; Wilke, 2010).

It is known that infectious diseases characterized by their specific signs and symptoms, as cholera and influenza, have reached different places in different times. During the last century the microbiology field has also shown the occurrence of less evident infectious diseases through laboratories that can identify the microorganisms associated with the diseases. Since the emergence of resistant bacteria has reached a critical condition, a new task has arise to microbiologists: starting testing in vitro bacteria resistance of strains isolated from patients, aiming to report which agents could still be used to cure that patients. Genes expressing resistance to different agents eventually emerged under pressure, spread to several bacteria species, and combine themselves to create totally untreatable strains until the development of a new drug (Högberg et al., 2010; O'Brien and Stelling, 2011).

The emergence and spread of bacteria resistance can be associated with many factors, but they always represent an evolution process: a response to selective pressure. The impact of this resistance can be substantial or insignificant, depending on the level of resistance, the infection site and the availability of effective therapies (Isturiz, 2010; Rice, 2009).

The emergence and dissemination of Gram-negative bacteria are associated to serious public health issues, which implicate in a continuous and update monitoring (Giamarellou, 2010; Giske and Cornaglia, 2010; Gould, 2009; Siegel, 2008; Souli et al., 2008). This concern can be detected in the current generation, which collects, groups and analyses all the information involving nature, dissemination and distribution of microorganisms and their resistance to antibiotics, aiming the improvement of life quality.

The bacteria resistance combat must be led by biologic scientists, although social researches play an important role in the behavior aspects of the problem. Both, patients and health professionals, should be aware that the increase in bacteria resistance is in part caused by inappropriate behavior in many factors, such as follow-up of medical therapy by the patient, self-medication, drug prescription, hand-washing in medical procedures, and others (Edgar et al., 2009; Huttner et al., 2010; Shrank et al., 2010).

\section{In What Can Our Future Rely On?}

The resistance to the available antibiotics is increasing in an alarming level. At the same time, the development of new antimicrobial agents is decreasing. With the emergence and dissemination of the resistance and the appearance of new bacterial pathogens, the urgency for the discovery of new drugs should be treated as a priority, associated with the new discoveries, surveillance and controlling programs, although the pharmaceuticals companies have decreased the development of new antibiotics (Bush, 2004; Högberg et al., 2010; Pankey, 2005).

During the past decade the efforts to combat multiresistant microorganisms were mainly focused in Grampositive bacteria and the pharmaceutical companies have developed new drugs to fight these organisms. Unfortunately, the growing problem of Gram-negative resistance was not parallel to the discovery of antibiotics to treat infections caused by these bacteria, resulting in a substantial number of untreatable infections and in the emergence of a disturbing perspective (Souli et al., 2008).

\section{A Hopeful Conclusion}

Every time our world faces a predictable, but inevitable tragic outcome, the first reaction is to join forces, to bring together all the information, knowledge and tools aiming the same result: the establishment of balance.

Doctors, microbiologists, pharmacists, pharmaceutical CEO's, researchers and the general public must share all the available data on antimicrobials, infections, therapy and public health threat of resistance. They must also engage their best efforts to follow the management therapies, programs and bacteria resistance councils.

Numerical reports are important, but in the midst of information apparently we are lacking experience reports, because with so many data, so many achievements, minor details get lost, and those are the ones that remain a ques- 
tion mark in geographically distant, but so close related laboratories. Minor results, difficulties, observations, chemicals, phenotypic and genotypic changes, and so many others, are as important and crucial as the numerical data, and unfortunately their exchange is being left behind by so many researchers and physicians.

From the public health point of view the antimicrobial resistance is a problem that requires campaigns mainly associated with health care professionals, but also a language that can reach the general public. In order to verify the economic impact on health care systems, an integrate council, formed by administrators, doctors, researches and economists should bring data from all the sectors involved aiming to discuss the best proposal treatment in common cases of infections, so that can reflect positively on the general budget distribution that reaches other sectors inside the health care systems.

Surveillance is a crucial factor in creating a path to reach the effects caused by resistance. Although surveillance exists worldwide, an integration of data is desperately needed, because many researchers are thinking regional, others national, but the aim is to think global not only in numerical data. International projects with multi-professional participants already exist, but the creation of other programs should continue and the ones that exist should comprise professionals from economic, administrative and social fields.

The threat of multi-resistant bacteria is a critical public health issue that requires a coordinated and multifaceted response, not excluding veterinarians, agriculturalists and media representatives. Feeding the webs of integrated information with the available data from all the participants fields we can minimize selective pressure, overcome the problems in new drugs development, implement a working management therapy, redirect the extra costs to an alternative supporting resistance program, so that in the future we may be able to maintain antimicrobial susceptibility patterns at a level we can live with.

All the proposals herein discussed, and others existent in so many studies are not impossible to achieve, because great minds inhabit our world and put together they can definitely be greater.

\section{Acknowledgments}

This study was supported by Fundação de Amparo à Pesquisa do Estado de São Paulo (FAPESP 2010/08695-0 and 2010/12841-1).

\section{References}

Ansari MI, Malik A (2009) Genotoxicity of agricultural soils in the vicinity of industrial area. Mutat Res 673:124-132.

Balsalobre LC, Dropa M, de Oliveira DE, Lincopan N, Mamizuka EM, Matté GR, Matté MH (2010) Presence of blatem-116 gene in environmental isolates of Aeromonas hydrophila and Aeromonas jandaei from Brazil. Braz J Microbiol 41:718-719.

Barbosa TM, Levy SB (2000) The impact of antibiotic use on resistance development and persistence. Drug Resist Updat 3:303-311.

Bush K (2004) Why it is important to continue antibacterial drug discovery. ASM News 70:282-287.

Coculescu BI (2009) Antimicrobial resistance induced by genetic changes. J Med Life 2:114-123.

Dropa M, Balsalobre LC, Lincopan N, Mamizuka EM, Cassettari VC, Matté GR, Matté MH (2009) Emergence of Klebsiella pneumoniae carrying the novel extended-spectrum betalactamase gene variants bla $\mathrm{SHV}_{\mathrm{S}-40}$, bla $\mathrm{TEM}_{\mathrm{TE}-116}$ and the class 1 integron-associated bla $\mathrm{GES}_{\mathrm{G}}$ in Brazil. Clin Microbiol Infect 51:203-209.

Edgar T, Boyd SD, Palamé MJ (2009) Sustainability for behaviour change in the fight against antibiotic resistance: a socialmarketing framework. J. Antimicrob Chemother 63:230-237.

Giamarellou H (2010) Multidrug-resistant Gram-negative bacteria: how to treat and for how long. Int $\mathrm{J}$ Antimicrob Agents 36 Suppl 2:S50-S54.

Giske CG, Cornaglia G (2010) ESCMID Study Group on Antimicrobial Resistance Surveillance (ESGARS). Supranational surveillance of antimicrobial resistance: The legacy of the last decade and proposals for the future. Drug Resist Updat 13:93-98.

Gottlieb T, Nimmo GR (2011) Antibiotic resistance is an emerging threat to public health: an urgent call to action at the Antimicrobial Resistance Summit. Med J Aust 194(6):281283.

Gould IM (2009) Antibiotic resistance: the perfect storm. Int J Antimicrob Agents 34 Suppl 3:S2-S5.

Högberg LD, Heddini A, Cars O (2010) The global need for effective antibiotics: challenges and recent advances. Trends Pharmacol Sci 31:509-515.

Huttner B, Goossens H, Verheij T, Harbarth S (2010) CHAMP consortium. Characteristics and outcomes of public campaigns aimed at improving the use of antibiotics in outpatients in high-income countries. Lancet Infect Dis 10:17-31.

Isturiz RE (2010) Optimizing antimicrobial prescribing. Int J Antimicrob Agents 36 Suppl 3:S19-S22.

Kouyos RD, Abel Zur Wiesch P, Bonhoeffer S (2011) On being the right size: the impact of population size and stochastic effects on the evolution of drug resistance in hospitals and the community. PLoS Pathog 7e1001334.

Kurek A, Grudniak AM, Kraczkiewicz-Dowjat A, Wolska KI (2011). New antibacterial therapeutics and strategies. Pol J Microbiol 60:3-12.

Lachmayr KL, Kerkhof LJ, DiRienzo G, Cavanaugh CM, Ford TE (2009) Quantifying nonspecific TEM $\beta$-lactamase (bla $\left.\mathrm{T}_{\text {TEM}}\right)$ genes in a wastewater stream. Appl Environ Microbiol 75:203-211.

Moura A, Henrique I, Ribeiro R, Correia A (2007) Prevalence and characterization of integrons from bacteria isolated from a slaughterhouse wastewater treatment plant. J Antimicrob Chemother 60:1243-1250.

Munir M, Xagoraraki I (2011) Levels of antibiotic resistance genes in manure biosolids, and fertilized soil. J Environ Qual 40:248-255. 
O'Brien TF, Stelling J (2011) Integrated multilevel surveillance of the world's infecting microbes and their resistance to antimicrobial agents. Clin Microbiol Rev 24:281-295.

Pankey GA (2005) Tigecycline. J Antimicrob Chemother $56: 470-480$.

Prado T, Pereira WC, Silva DM, Seki LM, Carvalho APDA, Asensi MD (2008) Detection of extended-spectrum $\beta$-lactamase-producing Klebsiella pneumoniae in effluents and sludge of a hospital sewage treatment plant. Lett Appl Microbiol 46:136-141.

Rice LB (2009) The clinical consequences of antimicrobial resistance. Curr Opin Microbiol 12:476-481

Santos RP, Mayo TW, Siegel JD (2008) Healthcare epidemiology: active surveillance cultures and contact precautions for control of multidrug-resistant organisms: ethical considerations. Clin Infect Dis 47:110-116.

Shrank WH, Choudhry NK, Fischer MA, Avorn J, Powell M, Schneeweiss S, Liberman JN, Dollear T, Brennan TA, Brookhart MA (2010) The epidemiology of prescriptions abandoned at the pharmacy. Ann Intern Med 153:633-640.

Siegel RE (2008) Emerging gram-negative antibiotic resistance: daunting challenges, declining sensitivities, and dire consequences. Respir Care 53:471-479.
Souli M, Galani I, Giamarellou H (2008) Emergence of extensively drug-resistant and pandrug-resistant Gram-negative bacilli in Europe. Euro Surveill 13(47):1-11.

Svara F, Rankin DJ (2011) The evolution of plasmid-carried antibiotic resistance. BMC Evol Biol 11:130.

Thomas J (2009) Antimicrobial Resistance: The "ignored" public health care threat. Board of pharmacy newsletter. Available at:

http://www.mdbop.org/whatsnew/antimicrobail\%20resista nce $\% 20 j \% 20$ thomas.pdf.

Wiesch PA, Kouyos R, Engelstädter J, Regoes RR, Bonhoeffer S (2011) Population biological principles of drug-resistance evolution in infectious diseases. Lancet Infect Dis 11:236247.

Wilke MH (2010).Multiresistant bacteria and current therapy - the economical side of the story. Eur J Med Res 15:571-576.

Wright GD (2010) Antibiotic resistance in the environment: a link to the clinic? Curr Opin Microbiol 13:589-594.

Zhang T, Zhang M, Zhang X, Fang HH (2009) Tetracycline resistance genes and tetracycline resistant lactose-fermenting Enterobacteriaceae in activated sludge of sewage treatment plants. Environ Sci Technol 43:3455-3460.

All the content of the journal, except where otherwise noted, is licensed under a Creative Commons License CC BY-NC. 